\title{
Uji Cemaran Salmonella sp. pada Susu Segar Kambing Sapera di Kecamatan Siliragung Kabupaten Banyuwangi
}

\author{
Rosdiyanah Ayu Aisiyah Putri ${ }^{*}$, Wiwiek Tyasningsih ${ }^{1}$, Faisal Fikri ${ }^{2}$ \\ ${ }^{1}$ Department of Veterinary Microbiology, Faculty of Veterinary Medicine, Universitas Airlangga \\ ${ }^{2}$ Department of Basic Veterinary Medicine, Faculty of Veterinary Medicine, Universitas Airlangga \\ *Corresponding author: rosdiyanah.ayu.aisiyah-2017@fkh.unair.ac.id
}

\begin{abstract}
Abstrak
Penelitian ini bertujuan untuk mengetahui keberadaan Salmonella sp. pada susu kambing Sapera segar di kecamatan Siliragung, kabupaten Banyuwangi. Pengambilan sampel susu kambing Sapera segar dilakukan pada bulan April 2021 sebanyak 17 sampel. Masing-masing sampel diambil sebanyak $25 \mathrm{ml}$ kemudian dilakukan pra pengkayaan dengan media Lactose Broth, lalu diperkaya dengan media Tetrathionate Broth, dan diisolasi pada media selektif antara lain Hectoen Enteric Agar, Xylose Lysine Deoxycholate Agar, dan Bismuth Sulfite Agar. Hasil identifikasi menunjukkan bahwa semua sampel susu kambing Sapera segar tidak mengandung Salmonella sp. Hal-hal yang perlu diperhatikan dalam pemerahan antara lain menyediakan fasilitas pemerahan, membersihkan kandang, mempersiapkan pemerahan, mengatur jarak dan waktu pemerahan, serta mencuci puting susu setelah proses pemerahan selesai. Peternak kambing di Siliragung telah melakukan serangkaian kebersihan sebelum memerah susu, seperti mencuci tangan dengan sabun, membersihkan ambing kambing dengan kain, dan mencuci wadah penampung susu segar, selain itu didukung oleh jenis kandang kambing berupa kandang panggung sehingga meminimalisir ambing dan puting terkontaminasi feses. Teknik pemerahan telah dilakukan dengan baik sehingga tidak ditemukan adanya Salmonella sp. tidak adanya kontaminasi menunjukkan kualitas susu yang baik untuk dikonsumsi.
\end{abstract}

Kata kunci: Kambing sapera, Salmonella sp., Susu kambing

\section{Abstract}

This study aims to determine the presence of Salmonella sp. on Sapera goat's milk in Siliragung Subdistrict, Banyuwangi. The sampling of fresh milk from Sapera goats in April 2021 was 17 samples. Each sample was taken as much as $25 \mathrm{ml}$ then pre-enriched with Lactose Broth media, enriched with Tetrathionate Broth media, and isolated on selective media including Hectoen Enteric Agar, Xylose Lysine Deoxycholate Agar, and Bismuth Sulfite Agar. The identification results showed that all samples of Sapera Goat's milk did not contain Salmonella sp. Things that need to be considered when milking include providing milking facilities, cleaning the cage, preparing for milking, adjusting the distance and time of milking, and washing the nipples after the milking process is complete. Goat breeders in Siliragung having carried out a series of hygiene before milking, such as washing hands with soap, cleaning goat udders with cloth, washing fresh milk containers, beside that it's also supported by the type of goatfold is stage to minimize the udder and nipples being contaminated with feces. The milking technique has been carried out well so there is no presence of Salmonella sp. The absence of contamination indicates the quality of the milk is good for consumption.

Keywords: Goat's milk, Salmonella sp., Sapera goat 
Prosiding Seminar Nasional Pembangunan dan Pendidikan Vokasi Pertanian

Politeknik Pembangunan Pertanian Manokwari, 31 Juli 2021

e ISSN : 2774-1982

DOI : https://doi.org/10.47687/snppvp.v2i1.186

\section{PENDAHULUAN}

Jenis ternak yang menghasilkan susu salah satunya yakni kambing perah. Razafindrakoto et al., (1994) menyatakan susu kambing memiliki kandungan gizi yang serupa dengan susu sapi. Pernyataan ini diperbarui oleh Ceballos et al., (2009) bahwa susu kambing memiliki khasiat lebih banyak dibandingkan dengan susu sapi, dikarenakan susu kambing memiliki butir lemak yang lebih kecil dan proporsi asam lemak rantai pendek yang relatif banyak dibandingkan susu sapi sehingga mudah dicerna.

Ratya (2017) menyatakan susu kambing memiliki khasiat diantaranya kecernaannya yang tinggi dan alergenisitas yang rendah. Susu kambing dapat menjadi salah satu susu alternatif selain susu sapi yang saat ini menjadi susu komersial. Moedji dkk. (2010) menyatakan khasiat dari susu kambing antara lain dapat membantu menekan pembiakan bakteri dalam tubuh sebab mempunyai sifat antiseptik alami. Susu kambing mengandung sodium, fluorine, kalsium, dan fosfor sehingga memiliki khasiat membantu pencernaan dan menetralisir asam lambung, menyembuhkan reaksi alergi pada kulit, saluran napas, dan pencernaan, menyembuhkan bermacam penyakit paru seperti asma, tuberkulosis, serta infeksi akut pada paru, menyembuhkan beberapa kelainan ginjal seperti nephrotic syndrom, infeksi ginjal, serta asam urat tinggi, kandungan kalsium yang tinggi dapat membantu menyembuhkan rematik dan mengobati osteoporosis, menambah vitalitas dan daya tahan tubuh, mengatasi masalah impotensi dan gairah seksual baik pada pria maupun wanita, serta memiliki efek antikanker.

Saleh (2004) menyatakan susu segar dapat menjadi medium yang baik untuk pertumbuhan dan perkembangan bakteri, sehingga susu segar dapat menjadi tidak layak untuk dikonsumsi bila tidak ditangani dengan baik dalam waktu singkat. Jawetz et al., (2013) memberikan penjelasan bakteri yang sering mengontaminasi susu segar antara lain Streptococcus lactis, Aerobacter aerogenes, Escherichia coli, Lactobacillus casei, dan Lactobacillus acidophilus. Poppe (2020) menyatakan susu segar atau yang tidak dipasteurisasi juga dapat terkontaminasi oleh Salmonella sp. yang merupakan bakteri patogen yang sifatnya zoonosis dan perlu mendapat perhatian pada kesehatan manusia dan hewan.

Susu segar adalah media yang sangat baik bagi pertumbuhan bakteri sehingga apabila kebersihannya tidak terjaga maka dapat membahayakan kesehatan konsumen dan menurunkan mutu serta keamanan susu. Jumlah bakteri tertentu dalam susu segar dapat digunakan sebagai bahan pertimbangan untuk menjamin konsumen menerima susu segar 
Prosiding Seminar Nasional Pembangunan dan Pendidikan Vokasi Pertanian

Politeknik Pembangunan Pertanian Manokwari, 31 Juli 2021

e ISSN : 2774-1982

DOI : https://doi.org/10.47687/snppvp.v2i1.186

berkualitas (Balia dkk., 2008). Jumlah bakteri yang terkandung dalam susu segar digunakan sebagai indikator pencemaran dan kualitas sanitasi susu segar. Batas maksimum cemaran mikroba pada susu segar yang tidak dipasteurisasi untuk diproses lebih lanjut maupun untuk dikonsumsi langsung harus negatif/25ml (Badan Standardisasi Nasional, 2009). Bakteri yang menyerang ternak dapat disebabkan oleh pemeliharaan hewan ternak yang kurang sehat dan bisa diakibatkan oleh kontaminasi silang antar pegawai kandang yang tidak menjaga higienitas personal (Poernomo, 1994).

Peternakan kambing perah di Kabupaten Banyuwangi salah satunya berada di Kecamatan Siliragung yang terletak di bagian selatan Kabupaten Banyuwangi. Data populasi ternak oleh Dinas Pertanian menunjukkan pada tahun 2020 terdapat total 3.992 ekor kambing. Populasi Kambing jenis Sapera di kecamatan Siliragung pada bulan Maret 2021 sebanyak 17 ekor. Masyarakat Siliragung mengonsumsi minuman yang berkhasiat bagi kesehatan tubuh salah satunya yakni susu kambing Sapera.

Peternakan kambing perah di kecamatan Siliragung telah dilakukan penelitian sebelumnya oleh Nanda (2019), yang meneliti jumlah bakteri yang mencemari susu kambing segar jenis Jawa Randu dengan total rata rata bakteri sebesar 5,4x10 $\mathrm{CFU} / \mathrm{ml}$ dari batas cemaran TPC $2 \times 10^{5} \mathrm{CFU} / \mathrm{ml}$ (Thai Agricultural Standar, 2008) namun belum terdapat penelitian yang menguji jumlah bakteri Salmonella sp. yang mencemari susu kambing segar jenis Sapera.

WHO (2014) menyatakan Salmonella sp. merupakan spesies bakteri penyebab utama penyakit bawaan makanan di seluruh dunia. Resiko penyakit akibat infeksi Salmonella sp. sangat besar dikarenakan kurangnya penyelidikan Salmonellosis di negara berkembang dan masih terbatas studi di laboratorium. Upaya penyediaan pangan asal hewan yang aman untuk dikonsumsi manusia telah diatur dalam Standar Nasional Indonesia tahun 2000 (SNI No. : 01 - 6366-2000) tentang batas maksimum cemaran mikroba dan batas maksimum residu pada bahan pangan asal hewan.

Menurut Standar Nasional Indonesia tahun 2000 (SNI No. : 01-6366-2000) mikroba Salmonella sp. harus negatif pada susu segar, apabila positif tercemar bakteri Salmonella sp. dan dikonsumsi manusia maka dapat menyebabkan gangguan sistem pencernaan (radang usus), infeksi sistemik, penurunan daya serap pada usus, dan demam, oleh sebab itu perlu dilakukan pengujian isolasi dan identifikasi bakteri untuk menguji cemaran bakteri Salmonella sp. pada susu kambing Sapera segar di kecamatan Siliragung sehingga dapat memberikan informasi kepada peternak, konsumen, dan pemerintah 
Prosiding Seminar Nasional Pembangunan dan Pendidikan Vokasi Pertanian

Politeknik Pembangunan Pertanian Manokwari, 31 Juli 2021

e ISSN : 2774-1982

DOI : https://doi.org/10.47687/snppvp.v2i1.186

kabupaten untuk meningkatkan pengawasan mutu susu sejak dihasilkan oleh peternak hingga sampai di tangan konsumen.

Tujuan dari dilakukannya penelitian ini yaitu untuk mengetahui adanya cemaran bakteri Salmonella sp. pada susu kambing Sapera di kecamatan Siliragung kabupaten Banyuwangi. Hasil penelitian ini berguna dalam pengembangan ilmu pengetahuan di bidang kesehatan masyarakat veteriner yaitu tentang cemaran bakteri Salmonella sp. pada susu kambing Sapera segar di kecamatan Siliragung kabupaten Banyuwangi. Penelitian ini juga dapat menjadi referensi cemaran bakteri Salmonella sp. pada susu kambing Sapera segar di kecamatan Siliragung kabupaten Banyuwangi sebagai bahan pertimbangan bagi pemerintah kabupaten Banyuwangi dalam penetapan kebijakan untuk melakukan pengawasan keamanan bahan pangan asal hewan yang lebih masif terutama susu segar yang dikonsumsi oleh masyarakat.

\section{METODE}

Penelitian dilakukan di laboratorium Unit Pelaksana Teknis Pengujian Mutu dan Pengembangan Produk Kelautan dan Perikanan (UPT PMP2KP) Banyuwangi. Penelitian dilaksanakan pada bulan Maret - April 2021 dengan pengambilan sampel susu kambing Sapera segar dilakukan di peternakan kambing perah di kecamatan Siliragung kabupaten Banyuwangi. Berdasarkan Standar Nasional Indonesia No.01-2332-2-2006 (SNI, 2006) pemeriksaan bakteri Salmonella sp. dapat dilakukan dengan tahapan uji pra pengkayaan, pengkayaan, isolasi, dan identifikasi.

Proses pengujian sampel dilakukan, media yang digunakan pada tahap pra pengayaan adalah Lactose Broth (LB). Tahap ini dilakukan sebagai pre enrichment broth pada bakteri Salmonella sp. Tahap pra pengkayaan yakni sampel susu kambing segar masing masing $25 \mathrm{ml}$ dimasukkan ke dalam erlenmeyer lalu tambahkan 225ml larutan LB lalu diinkubasi pada suhu $35^{\circ} \mathrm{C}$ selama 24 jam. Kekeruhan pada media LB setelah diinkubasi menunjukkan bahwa terjadi pertumbuhan bakteri (Saptarini, 2009).

Tahap selanjutnya adalah pengayaan menggunakan media Tetrationate Broth (TTB). Senyawa selektif dalam TTB yaitu garam empedu dapat menghambat pertumbuhan bakteri Gram positif. Tetrationat terbentuk di dalam media karena adanya penambahan kalium iodide (I2KI). Bakteri Salmonella sp. dapat tumbuh dalam media TTB karena memiliki enzim tetrationat reduktase.

Bakteri yang tumbuh pada media TTB yang telah diinkubasi diinokulasikan pada media HE, XLD, dan BSA menggunakan jarum ose $(3 \mathrm{~mm})$. Biakan bakteri pada media 
Prosiding Seminar Nasional Pembangunan dan Pendidikan Vokasi Pertanian

Politeknik Pembangunan Pertanian Manokwari, 31 Juli 2021

e ISSN : 2774-1982

DOI : https://doi.org/10.47687/snppvp.v2i1.186

HE, XLD dan BSA diinkubasi pada suhu $42^{\circ} \mathrm{C}$ selama 24 jam. Koloni yang diduga Salmonella sp. yang diisolasi pada media HE menunjukkan koloni berwarna hijau kebiruan dengan atau tanpa titik hitam. Koloni yang diduga Salmonella sp. yang diisolasi pada media XLD akan terlihat perubahan berwarna merah muda dengan atau tanpa titik mengkilat atau terlihat hampir seluruh koloni berwarna hitam. Koloni yang diduga Salmonella sp. yang diisolasi pada media BSA akan terlihat berwarna keabuabuan atau kehitaman, metalik, dan media di sekitar koloni berwarna coklat hingga hitam.

Hasil isolasi yang mencirikan koloni terduga Salmonella sp. selanjutnya dilakukan uji identifikasi pada media identifikasi, antara lain TSIA dan LIA. Koloni yang diduga Salmonella sp. diambil dari masing-masing media agar selektif setelah 24 jam inkubasi, lalu diinokulasikan ke media TSIA dan LIA dengan cara ditusuk ke dalam media agar, selanjutnya digores pada media agar miring, selanjutnya diinkubasi pada suhu $35^{\circ} \mathrm{C}$ selama 24 jam. Kultur Salmonella sp. pada TSIA yang khas memberikan reaksi alkaline (merah) pada goresan agar miring dan asam (kuning) pada tusukan agar tegak, dengan atau tanpa H2S (warna kehitaman pada agar). Pada LIA, kultur Salmonella sp. yang khas memberikan reaksi alkaline (ungu) pada keseluruhan tabung. Umumnya kultur Salmonella sp. membentuk H2S pada TSIA dan LIA.

Hasil identifikasi koloni yang positif Salmonella sp. dilakukan uji lanjutan yaitu uji biokimia dan uji serologis. Uji biokimia antara lain uji urease, uji indole, uji Voger Proskauer, Uji Methyl Red, uji citrate, uji Lysine Decarboxylase Broth, uji kalium cyanida, dan uji gula gula.Uji serologis antara lain uji polyvalent somatic $(\mathrm{O})$ dan uji polyvalent flagelar $(\mathrm{H})$.

\section{HASIL DAN PEMBAHASAN}

Sampel susu kambing Sapera pada penelitian ini berasal dari empat peternakan yang tersebar di kecamatan Siliragung. Sebanyak empat sampel berasal dari peternakan A, satu sampel dari peternakan B, dua sampel dari peternakan C, dan 10 sampel dari peternakan D. Lokasi peternakan tempat pengambilan sampel dipilih berdasarkan peternakan yang terdapat kambing Sapera di kecamatan Siliragung. Hasil isolasi keseluruhan rangkaian uji tersebut menghasilkan Salmonella sp. negatif atau tidak ditemukan bakteri Salmonella sp. pada susu kambing Sapera segar, dapat dilihat pada tabel 1. 
Prosiding Seminar Nasional Pembangunan dan Pendidikan Vokasi Pertanian

Politeknik Pembangunan Pertanian Manokwari, 31 Juli 2021

e ISSN : 2774-1982

DOI : https://doi.org/10.47687/snppvp.v2i1.186

Tabel 1. Hasil identifikasi pemeriksaan cemaran Salmonella sp.

\begin{tabular}{lccc}
\hline No & Kode Sampel & Lokasi & Hasil \\
\hline 1. & A1 & Peternakan A & Negatif \\
2. & A2 & Peternakan A & Negatif \\
3. & A3 & Peternakan A & Negatif \\
4. & A4 & Peternakan A & Negatif \\
5. & B1 & Peternakan B & Negatif \\
6. & C1 & Peternakan C & Negatif \\
7. & C2 & Peternakan C & Negatif \\
8. & D1 & Peternakan D & Negatif \\
9. & D2 & Peternakan D & Negatif \\
10. & D3 & Peternakan D & Negatif \\
11. & D4 & Peternakan D & Negatif \\
12. & D5 & Peternakan D & Negatif \\
13. & D6 & Peternakan D & Negatif \\
14. & D7 & Peternakan D & Negatif \\
15. & D8 & Peternakan D & Negatif \\
16. & D9 & Peternakan D & Negatif \\
17. & D10 & Peternakan D & Negatif \\
\hline
\end{tabular}

Berdasarkan data tabel 1 menunjukkan seluruh sampel susu kambing Sapera segar yang diisolasi menunjukkan hasil negatif yakni tidak ditemukan adanya cemaran Salmonella sp. Tidak adanya koloni Salmonella sp. dalam sampel yang diuji dapat dilihat dari ciri koloni terduga Salmonella sp. pada masing masing media.

Koloni terduga positif Salmonella sp. pada media HE memiliki ciri koloni berwarna hijau kebiruan dengan bintik hitam di tengah koloni (Umidayati dkk, 2020). Hasil isolasi dari sampel susu kambing Sapera segar pada media HE menunjukkan koloni yang tumbuh berwarna putih yang artinya tidak mencirikan pertumbuhan koloni terduga Salmonella sp. Hasil isolasi pada media HE dapat dilihat pada gambar 1.

Koloni terduga positif Salmonella sp. pada media XLD memiliki ciri koloni berwarna merah muda dengan bintik hitam di tengah koloni (Umidayati dkk, 2020). Hasil isolasi dari sampel susu kambing Sapera segar pada media XLD menunjukkan koloni yang tumbuh berwarna putih yang artinya tidak mencirikan pertumbuhan koloni terduga Salmonella sp. Hasil isolasi pada media XLD dapat dilihat pada gambar 2

Koloni terduga Salmonella sp. pada media BSA menunjukkan ciri koloni berwarna hitam dan cenderung memperlihatkan kilau metalik (Rinihapsari, 2003). Hasil isolasi dari sampel susu Kambing Sapera segar pada media BSA menunjukkan koloni berwarna putih dimana tidak mencirikan koloni Salmonella sp. (lihat pada gambar 3). 


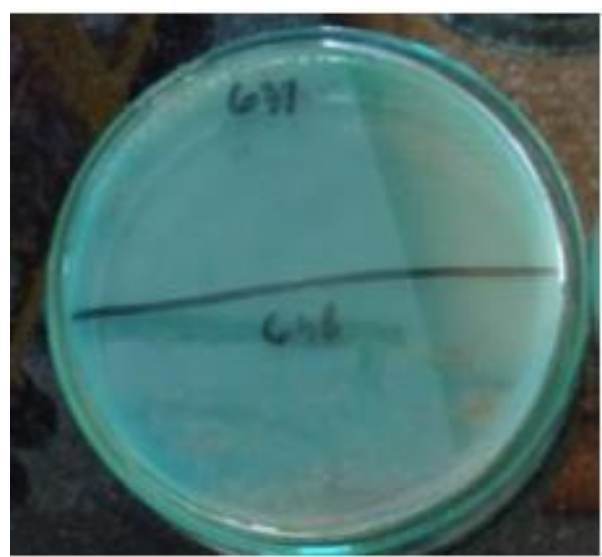

Gambar 1. Koloni bakteri Koloni bakteri pada media $\mathrm{HE}$

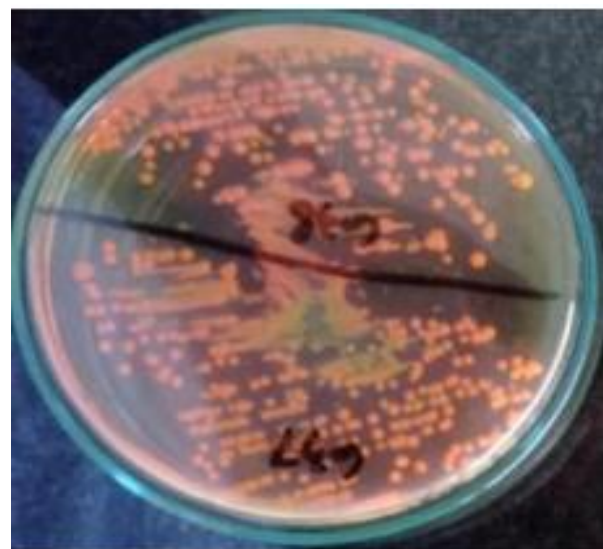

Gambar 2. Koloni bakteri pada media XLD

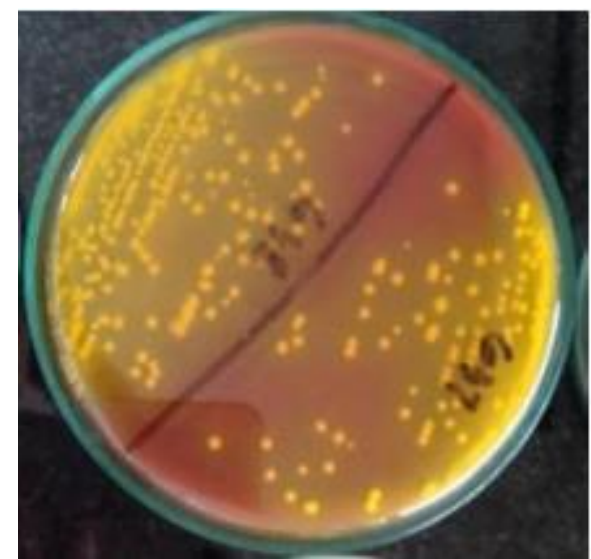

Gambar 3. Koloni bakteri pada media BSA

Isolasi pada media selektif yang ditunjukkan oleh gambar 1, gambar 2, dan gambar 3 pada media HE, XLD, dan BSA menunjukkan koloni bakteri yang tumbuh berwarna putih yang artinya tidak adanya koloni terduga Salmonella sp., sehingga tidak dilanjutkan uji identifikasi yakni uji biokimia dan uji serologis.

Hasil dari isolasi 17 sampel susu Kambing Sapera segar yang diinkubasi pada media HE, XLD, maupun BSA tidak menunjukkan koloni yang mencirikan Salmonella sp. di mana semua koloni menunjukkan warna putih. Jelaskan warna2 he xld bsa dgn sumber. Adanya pencemaran Salmonella sp. pada susu kambing segar dipengaruhi oleh beberapa faktor. Menurut Jorgensen et al., (2005) faktor - faktor yang mempengaruhi pencemaran Salmonella sp. pada susu segar tergantung pada higienitas dan sanitasi dari tangan dan baju pemerah, alat perah, kandang, peralatan penampung susu (ember, lap, saringan), dan penyakit tertentu pada hewan. 
Prosiding Seminar Nasional Pembangunan dan Pendidikan Vokasi Pertanian

Politeknik Pembangunan Pertanian Manokwari, 31 Juli 2021

e ISSN : 2774-1982

DOI : https://doi.org/10.47687/snppvp.v2i1.186

Nurhayati dkk, (2017) menyatakan Salmonella sp. dapat tumbuh pada suhu $15^{\circ} \mathrm{C}$ dan optimum tumbuh pada suhu $37^{\circ} \mathrm{C}$. Berdasarkan data BMKG (2021) suhu udara di kecamatan Siliragung antara $24^{\circ} \mathrm{C}-32^{\circ} \mathrm{C}$, sehingga terdapat kemungkinan Salmonella sp. tidak berkembang biak secara optimum.

Salmonella sp. sering mengontaminasi makanan diantaranya telur dan hasil olahannya, ikan dan hasil olahannya, daging ayam, daging sapi, serta susu dan hasil olahannya seperti es krim dan keju (Jay et al., 2005). Kontaminasi oleh bakteri dapat berasal dari kotoran, darah, dan cairan yang keluar dari viscera yang kemudian dapat menempel pada lantai, ambing, maupun peralatan yang digunakan sehingga dapat mencemari produk yang dihasilkan. Pelaksanaan dan penyediaan susu segar saat pemerahan merupakan salah satu penentu dari kualitas dan keamanan susu. Mutu dan keamanan susu yang dihasilkan dipengaruhi oleh sanitasi dan higienitas serta penanganan ternak dan susu di peternakan (Balia dkk, 2008).

Semua sampel susu kambing Sapera segar di kecamatan Siliragung yang diuji tidak ditemukan adanya bakteri Salmonella sp. sehingga telah sesuai dengan SNI No. 01-63662000 yakni batas maksimum cemaran mikroba Salmonella sp. harus negatif $/ 25 \mathrm{ml}$ pada susu segar. Tidak ditemukannya koloni terduga Salmonella sp. menunjukkan sampel sampel tersebut telah memenuhi SNI No. 01-6366-2000 yakni batas maksimum cemaran mikroba Salmonella sp. harus negatif/25ml pada susu segar (Direktorat Kesehatan Masyarakat Veteriner, 2007). Beberapa hal yang perlu diperhatikan saat pemerahan antara lain menyediakan sarana pemerahan, membersihkan kandang, persiapan pemerah, mengatur jarak dan waktu pemerahan, serta mencuci puting setelah proses pemerahan selesai (Navyanti, 2015).

Bakteri Salmonella sp. tidak ditemukan dalam susu kambing Sapera segar sebab kandungan susu kambing yang banyak khasiatnya, salah satunya fluorin yang terkandung dalam susu. Moedji dkk. (2010) menyatakan susu kambing dapat membantu menekan pembiakan bakteri dalam tubuh sebab mempunyai sifat antiseptik alami. Antiseptik alami ini berasal dari fluorin dalam susu kambing yang jumlahnya berkisar 10 sampai 20 kali lipat lebih banyak daripada dalam susu sapi.

Mirawati dkk. (2013) menyatakan cemaran Salmonella sp. dapat terjadi akibat sanitasi dan higienitas yang buruk, sehingga dibutuhkan pengetahuan cara mencegah terjadinya cemaran Salmonella sp. bagi para peternak dan pemerah. Saerah (2017) 
Prosiding Seminar Nasional Pembangunan dan Pendidikan Vokasi Pertanian

Politeknik Pembangunan Pertanian Manokwari, 31 Juli 2021

e ISSN : 2774-1982

DOI : https://doi.org/10.47687/snppvp.v2i1.186

menyatakan sanitasi yang berpengaruh adalah sanitasi kandang dan lingkungan, sanitasi ternak, sanitasi peralatan pemerahan, dan higienitas pemerah.

Pemerah kambing Sapera di kecamatan Siiragung telah melaksanakan tata cara pemerahan yang baik, diantaranya kandang tempat memerah dipastikan selalu bersih. Pembersihan kandang dilakukan setiap hari berupa sanitasi kering yaitu menyapu feses dan urin kambing dengan sapu lidi dan dikumpulkan menjadi satu sebelum dilakukan pengolahan limbah. Menurut BPTP-Ungaran (2000) sanitasi kandang merupakan kegiatan pencegahan yang meliputi kebersihan kandang dan lingkungannya dalam rangka untuk menjaga kesehatan ternak sekaligus pemiliknya. Soediarto (2020) menyatakan sanitasi kandang dan lingkungan dapat diupayakan dengan menjaga kebersihan tempat pakan dan tempat minum, selain itu pengelolaan limbah feses dan urine ternak juga harus dibersihkan secara berkala.

Pemerah susu kambing Sapera segar mempersiapkan sarana pemerahan antara lain lap basah yang digunakan sebelum melakukan pemerahan untuk mengelap bagian puting dan ambing kambing supaya bersih, persiapan wadah botol penampung susu segar yang sebelumnya telah dicuci terlebih dahulu dengan air bersih mengalir, serta menjaga kebersihan tubuh kambing. Pemerah memberikan jarak antar pemerahan yang cukup berupa dua kali sehari yakni ketika pagi dan sore. Setelah proses pemerahan, pemerah mencuci puting kambing dengan cara teat dipping yaitu tindakan pencelupan puting ke dalam antiseptik dengan tujuan agar bakteri yang ada di sekitar puting tidak mencemari susu pada pemerahan selanjutnya. Dwita (2016) menyatakan sanitasi ternak dapat dilakukan dengan memandikan ternak tiap sepekan sekali, tujuannya adalah agar ternak selalu sehat dan terjaga kebersihannya sehingga tidak berpengaruh terhadap kualitas susu yang dihasilkan. Suresti (2018) menyatakan sanitasi peralatan pemerahan dapat dilakukan dengan menjaga kebersihan peralatan penampungan pemerahan susu segar dengan cara dicuci setiap selesai digunakan supaya tidak menjadi tempat berkembangnya bakteri.

Faktor higienitas personal (pemerah) juga berpengaruh pada hasil keberadaan bakteri, pemerah melakukan cuci tangan sebelum dan sesudah melakukan pemerahan, selain itu pemerah juga menjaga kebersihan selama melakukan pemerahan dengan tidak sedang merokok dan tidak meludah sembarangan. Cahyono dkk. (2013) menyatakan bahwa kontaminasi pemerah seringkali berasal dari tangan pemerah itu sendiri karena kebersihan tangan pemerah sering tidak diperhatikan, sehingga disarankan yaitu pemerah mencuci tangan sebelum dan sesudah melakukan pemerahan. 
Prosiding Seminar Nasional Pembangunan dan Pendidikan Vokasi Pertanian

Politeknik Pembangunan Pertanian Manokwari, 31 Juli 2021

e ISSN : 2774-1982

DOI : https://doi.org/10.47687/snppvp.v2i1.186

Upaya menjaga sanitasi juga didukung oleh tipe kandang kambing berupa kandang panggung untuk meminimalisir ambing dan puting terkontaminsasi feses. Teknis pemerahan telah dilakukan dengan baik oleh pemerah susu kambing Sapera di kecamatan Siliragung sehingga tidak dit emukan adanya cemaran bakteri Salmonella sp. Tidak adanya kontaminasi menunjukkan kualitas susu yang diperah cukup baik dan baik untuk dikonsumsi.

\section{KESIMPULAN DAN SARAN}

Dari hasil penelitian ini dapat disimpulkan bahwa tidak terdapat cemaran bakteri Salmonella sp. pada susu segar kambing Sapera di kecamatan Siliragung kabupaten Banyuwangi. Saran yang dapat diberikan yakni perhatian akan kebersihan dan higienitas pada semua rangkaian proses pemerahan susu segar harus tetap diperhatikan meskipun hasil penelitian tidak menunjukkan adanya kontaminasi Salmonella sp. Diharapkan adanya pembinaan lebih lanjut berupa sosialisasi dan pendampingan kepada para pemerah dan peternak supaya terjamin kualitas dan keamanan susu segar yang dikonsumsi oleh konsumen.

\section{UCAPAN TERIMA KASIH}

Peneliti mengucapkan terima kasih pada pihak - pihak yang telah membantu dalam terlaksananya penelitian ini.

\section{DAFTAR PUSTAKA}

Badan Standardisasi Nasional. (2009). Batas Maksimum Cemaran Mikroba dalam Makanan.

Balai Pengkajian Teknologi Pertanian Ungaran. (2000). Sanitasi Kandang Sapi Perah. Ungaran, Jawa Tengah. Jurnal Liptan BPTP Ungaran

Balia, R. L., Harlia, E., \& Suryanto, D. (2008). Jumlah bakteri total dan koliform pada susu segar peternakan sapi perah rakyat dan susu pasteurisasi tanpa kemasan di pedagang kaki lima. Fakultas Peternakan Universitas Padjadjaran, Bandung.

Cahyono, D. (2013). Kajian Kualitas Mikrobiologis (Total Plate Count (TPC), Enterobacteriaceae dan Staphylococcus Aureus) Susu Sapi Segar di Kecamatan Krucil Kababupaten Probolinggo. Dissertation. Universitas Brawijaya.

Ceballos, L.S., Morales, E.R., Adarve, G.D.L.T. Castro., J.D. Martinez, L.P., \& M R.S. Sampelayo. (2009). Composition of goat and cow milk produced under similar conditions and analyzed by identical methodology. J. food. Comp. Analysis. 22 : 322-329.

Direktorat Kesehatan Masyarakat Veteriner. (2007). Batas Maksimal Cemaran Mikroba dalam Bahan Makanan Asal Hewan (SNI No. 01-6366-2000). Jakarta. 
Prosiding Seminar Nasional Pembangunan dan Pendidikan Vokasi Pertanian

Politeknik Pembangunan Pertanian Manokwari, 31 Juli 2021

e ISSN : 2774-1982

DOI : https://doi.org/10.47687/snppvp.v2i1.186

Dwita, H., Lubis, S.N., \& Kusuma, S.I. (2016). Analisis Usaha Ternak Kambing Etawa (Studi Kasus: Desa Paya Geli Kecamatan Sunggal Kabupaten Deli Serdang). Journal of Agriculture and Agribusiness Socioeconomics, 5(1), 95130.

Jawetz, E., Melnick, J.L., \& Adelberg, E.A. (2013). Medizinische Mikrobiologie. SpringerVerlag.

Jay, J.M., Loessner, M.J., \& Golden, D.A. (2005). Foodborne gastroenteritis caused by Salmonella and Shigella. Modern Food Microbiology, 619-636.

Jorgensen, H, J.T. Mork, H.R. Hogasen, \& L.M. Rorvik. (2005). Enterotoxigenic Staphylococcus aureus in bulk in Norway. J. Appl. Microbiol (99): 158-166.

Mirawati, M., Lestari, E., \& Djajaningrat, H. (2013). Identifikasi Salmonella pada Jajanan yang Dijual di Kantin dan Luar Kantin Sekolah Dasar. Jakarta.

Moedji, R.D. \& Wiryanta, B.T.W. (2010). Manfaat Susu Kambing Etawa. Depok (ID). PT Agro Media Pustaka.

Nanda, E.R.V. (2019). Uji Jumlah Total Bakteri pada Susu kambing segar Jawa Randu di Kecamatan Siliragung Kabupaten Banyuwangi. Dissertation. Universitas Airlangga.

Navyanti, F. \& Adriyani, R. (2015). Higiene Sanitasi, Kualitas Fisik dan Bakteriologi Susu Sapi Segar Perusahaan Susu X di Surabaya. Jurnal kesehatan lingkungan, 8(1), 36-47.

Nurhayati, N. \& AGS, D.A. (2017). Daya Terima dan Kandungan Mutu Bakso Ikan KambingKambing (Abalistes stellaris) dengan Penambahan Asap Cair dan Simpan Pada Suhu Dingin. Acta Aquatica: Aquatic Sciences Journal, 4(2), 59-62.

World Health Organization. (2014). Drug Resistant Salmonella. http://www.who.int/. Diakses pada April 2020

Poernomo, S. (1994). Salmonella pada ayam di rumah potong ayam dan lingkungannya di wilayah Jakarta dan sekitarnya: Prosiding Seminar Nasional Teknologi Veteriner untuk Meningkatkan Kesehatan Hewan dan Pengamanan Bahan Pangan Asal Ternak. Bogor.

Poppe, C. (2020). Pathogens in Milk: Salmonella spp., Reference Module in Food Science, Elsevier. https://doi.org/10.1016/B978-0-08-100596-5.22968-5.

Ratya, N., Taufik, E., \& Arief, I.I. (2017). Karakteristik Kimia, Fisik dan Mikrobiologis Susu Kambing Peranakan Etawa di Bogor. Jurnal Ilmu Produksi dan Teknologi Hasil Peternakan, 5(1), 1-4.

Razafindrakoto, O., Ravelomanana, N., Rasolofo, A., Rakotoarimanana, R. D., Gourgue, P., Coquin, Pierre., Briend, \& Desjeux, J. F. (1994). Goat's milk as a substitute for cow's milk in undernourished children: a randomized double-blind clinical trial. Pediatrics English Edition, 94(1), 65-69.

Rinihapsari, E. (2003). Detection of Salmonella on Fried Rice Served in Restaurant of Economic Class Train. Jurnal Teknologi dan Industri Pangan, 14(3), 253-253.

Saerah, A.S. (2017). Hubungan Sanitasi Peternakan terhadap Tingkat Kejadian Penyakit Mastitis pada Sapi Perah Di Peternakan Rakyat Dusun Jambuer Kampungbaru Desa Balesari Kecamatan Ngajum Malang. Dissertation. Universitas Airlangga. 
Prosiding Seminar Nasional Pembangunan dan Pendidikan Vokasi Pertanian

Politeknik Pembangunan Pertanian Manokwari, 31 Juli 2021

e ISSN : 2774-1982

DOI : https://doi.org/10.47687/snppvp.v2i1.186

Saleh, E. (2004). Dasar Pengolahan Susu dan Hasil Ikutan Ternak. Program Studi Produksi Ternak. Fakultas Pertanian. Universitas Sumatera Utara.

Saptarini, K. (2009). Isolasi Salmonella spp. pada Sampel Daging Sapi di Wilayah Bogor serta Uji Ketahanannya terhadap Proses Pendinginan dan Pembekuan.

Soediarto, P., Astuti, T.Y., \& Syamsi, A.N. (2020). Peningkatan Kualitas Susu di Kelompok Peternak Sapi Perah 'Andini Lestari'Melalui Perbaikan Sanitasi Kandang dan Higiene Pemerahan. Prosiding, 9(1).

Standar Nasional Indonesia. (2000). Batas Maksimum Cemaran Mikroba dan Batas Maksimum Residu Pada Bahan Makanan Asal Hewan. Badan Standarisasi Nasional Indonesia. SNI 01-6366.

Standar Nasional Indonesia. (2006). Penentuan Salmonella sp. pada Produk Perikanan. Jakarta: Badan Standardisasi Nasional.SNI: 01-2332. 2-2006.

Thai Agricultural Standard. (2008). Raw Goat Milk. National Bureau of Agricultural Commodity and Food Standards, Ministry of Agriculture and Cooperatives. ICS 67.100.01.Published in the Royal Gaze tte Vol. 125 Section 139 D. Thailand.

Umidayati, U., Rahardjo, S., Ilham, I., \& Mulyono, M. (2020). Identifikasi Salmonella sp. pada Cacing Sutra (Tubifex sp.) Tangkapan dari Alam dan Hasil Budidaya. Journal of Aquaculture and Fish Health, 9(2), 122-130.

United States of Food and Drug Administration. (2017). FDA Investigates Multiple Salmonella Outbreak Strains Linked to Papayas. https://www.fda.gov/food/outbreaksfoodborneillness/fdainvestigatesmultiplesalmonella-outbreak-strains-linked-papayas. Diakses tanggal 1 Oktober 2020. 